\title{
Investigation of Withania Somnifera Extract as Corrosion Inhibitor for Copper in Nitric Acid Solutions
}

\author{
H.M. Elabbasy \\ Misr higher Institute for Engineering and Technology, Mansoura, Egypt \\ E-mail: helabbasy@hotmail.com
}

doi: $10.20964 / 2019.06 .23$

Received: 8 February 2019 / Accepted: 13 March 2019 / Published: 10 May 2019

Corrosion inhibitive effect of Withania Somnifera extract has been studied in $0.5 \mathrm{M}$ nitric acid for Copper $(\mathrm{Cu})$. The studies were done at different temperatures $\left(30-50^{\circ} \mathrm{C}\right)$. The thermodynamic parameters were determined. Withania Somnifera has been found to be more effective corrosion inhibitor at lower temperatures and inhibition efficiency (IE) reached $91.8 \%$ at $25 \mathrm{ppm}$. Adsorption isotherm was determined and was found to follow Frumkin adsorption isotherm. Inhibition efficiencies at different Withania Somnifera concentrations were determined using chemical and electrochemical techniques. Polarization data revealed that this extract acts as a mixed-kind inhibitor. The obtained inhibition efficiencies were in a high agreement, confirming the validity of the used techniques in testing the inhibitory action of Withania Somnifera for $\mathrm{Cu}$ corrosion in nitric acid medium.

Keywords: Withania Somnifera, Nitric acid, Frumkin adsorption isotherm, EIS, SEM.

\section{FULL TEXT}

(C) 2019 The Authors. Published by ESG (www.electrochemsci.org). This article is an open access article distributed under the terms and conditions of the Creative Commons Attribution license (http://creativecommons.org/licenses/by/4.0/). 